\title{
Concepções de Corpus de Análise na Pesquisa em Educação em Ciências Naturais: Uma Investigação em Dissertações e Teses de um Programa de Pós-Graduação
}

\author{
Conceptions of Corpus for Analysis in Science Education \\ Research: An Investigation in Dissertations and Theses from \\ a Graduate Program
}

\section{Concepciones sobre el Corpus de Análisis en la Investigación en Educación Científica: Una Búsqueda Científica en Disertaciones y Tesis de un Programa de Posgrado}

\author{
Julio Murilo Trevas dos Santos \\ Neide Maria Michelan Kiouranis \\ Brasil \\ Brasil
}

Investigaram-se neste trabalho compreensões e concepções sobre corpus de análise em dissertações e teses de um programa de pós-graduação em Educação em Ciências e Matemática. Buscou-se então: avaliar a ocorrência dessas compreensões e categorizá-las; identificar polissemia em relação ao termo corpus; avaliar as compreensões em função de referenciais teóricos de análise textual. As dissertações e as teses foram integralmente organizadas em corpora. Processaram-se os corpora por meio de análise textual auxiliada por computador (CATA), em um processo que envolveu métodos quantitativos e qualitativos. Utilizou-se o servidor Voyant Tools, um ambiente Web de análise de corpora extensos. A análise dos corpora resultou em quatro categorias a posteriori: caracterização do corpus; definição do corpus; formação do corpus; e operação sobre o corpus. Embora os resultados indiquem que as compreensões estavam vinculadas às metodologias de análise textual, perceberam-se inconsistências, afastamentos de referenciais teóricos e a necessidade de critérios para a constituição de corpora.

Palavras-chave: Análise de Corpora; Análise de Conteúdo; Análise Textual.

In this work, we investigate the understandings and conceptions of corpus for analysis in dissertations and theses of a graduate program in Science and Mathematics Education. Our goal is to evaluate the occurrence of these understandings and categorize them; to identify polysemy in relation to the term "corpus"; to evaluate understandings according to benchmarks of theoretical textual analysis. The dissertations and theses were organized 
entirely in corpora, which were processed through computer-aided textual analysis (CATA) in a process that involved quantitative and qualitative methods. For this, we used the Voyant Tools server, a web-based environment for extensive corpora analysis. The results pointed to four a posteriori categories: corpus characterization, definition formation and operation. Although the results indicate that the understandings were linked to methodologies of textual analysis, we found inconsistencies, deviations from theoretical benchmarks and the need for criteria for corpora development.

Keywords: Corpora Analysis; Content Analysis; Textual Analysis.

En este trabajo se investigó las comprensiones y concepciones sobre el corpus de análisis en disertaciones y tesis de un programa de posgrado en Educación en Ciencias y Matemáticas. El objetivo era evaluar la ocurrencia de estos entendimientos y clasificarlos; identificar polisemia en relación con el término corpus; evaluar las comprensiones en función de las referencias teóricas del análisis textual. Las disertaciones y tesis fueron totalmente organizadas en corpora. Los corpora se procesaron mediante análisis textual asistido por computadora (CATA), en un proceso que involucraba métodos cuantitativos y cualitativos. Se utilizó el servidor Voyant Tools, un entorno web de análisis de corpora extenso. El análisis de los corpora resultó en cuatro categorías a posteriori: caracterización del corpus; definición del corpus; formación del corpus; y operación en el corpus. Aunque los resultados indican que los entendimientos estaban vinculados a metodologías de análisis textual, se percibieron inconsistencias, desviaciones de las referencias teóricas y la necesidad de criterios para la constitución de corpus.

Palabras clave: Análisis de Corpora; Análisis de Contenido; Análisis Textual.

\section{Introdução}

Metodologias e técnicas de análise textual são muito utilizadas nas pesquisas na área de Educação em Ciências Naturais (Oliveira et al. 2003; Pinhão \& Martins, 2009; Santos et al., 2018). De um modo geral, três análises se destacam: a Análise de Conteúdo (AC); a Análise de Discurso (AD); e a Análise Textual Discursiva (ATD) (Chrysostomo \& Messeder, 2017; Santos et al., 2017). Essas análises se diferenciam em seus objetivos, mas mantêm alguns elementos comuns. Conforme discussão de Rocha e Deusdará (2005), existem aproximações e afastamentos entre essas análises. O foco deste trabalho está em um desses elementos comuns que pode estabelecer aproximação: o corpus de análise.

A preocupação com corpus é consequência da preocupação com a qualidade da análise e da pesquisa em que ela está inserida. A qualidade mencionada não se refere ao dualismo (Gamboa, 2003) pesquisa qualitativa e pesquisa quantitativa, mas às características que tornam a pesquisa reconhecida e aceita pelo meio acadêmico. Neste trabalho, se adota uma perspectiva de pesquisa qualitativa de métodos mistos, ou seja, que pode incorporar tanto métodos qualitativos, quanto métodos quantitativos. 
Contudo, admite-se que as discussões do dualismo permeiam as concepções e os critérios de qualidade.

Se existe uma relação entre corpus e a qualidade, quer seja da análise ou da pesquisa, surgem as dúvidas se um corpus deve ser compreendido como um critério para uma análise e se deve ser elaborado segundo critérios. Bauer e Gaskell (2015, p. 478) por exemplo, criticaram a representatividade, a fidedignidade, a validade e a amostragem como critérios de qualidade da pesquisa qualitativa. Esses autores propuseram "critérios com equivalência funcional à tradição quantitativa” (Bauer \& Gaskell, 2015, p. 480), dentre os quais consta a "construção do corpus" (Bauer \& Gaskell, 2015, p. 481) como equivalente à validade interna. Orlandi (2015, p. 60), como outro exemplo, não caracterizou um corpus como critério de qualidade de uma pesquisa. A autora afirmou que uma das primeiras etapas de uma $\mathrm{AD}$ é a constituição e a delimitação, segundo critérios teóricos, de um corpus. Complementando, Bauer e Aarts (2015, p. 61) e Bardin (2011, p. 126) apresentaram passos e regras para a constituição de um corpus.

A dúvida sobre corpus e as diferentes abordagens nos exemplos citados sugeriram uma pergunta: como são as compreensões e/ou concepções de pesquisadores sobre corpus para uma análise textual? Algumas suposições para a resposta foram: compreensão de corpus vinculada à metodologia de análise adotada; uma concepção de corpus comum às metodologias de análise; concepções de corpus desvinculadas de teorias e metodologias de análise, baseadas em senso comum ou representações de comunidades de pesquisa; falta de compreensão ou concepção sobre o corpus.

Efetivamente, a pergunta supracitada surgiu no desenvolvimento de uma pesquisa que concilia métodos mistos de análise textual. Tornou-se uma necessidade na mencionada pesquisa, dirimir a dúvida sobre o corpus para permitir o estabelecimento de alguns requisitos de confiabilidade e validade da abordagem analítica adotada. Sabese que as análises textuais são realizadas por muitos pesquisadores de várias áreas de conhecimento. É inviável em um curto período de tempo realizar uma investigação envolvendo um número representativo (abrangência regional ou nacional) desses pesquisadores. No intuito de tentar responder a pergunta e considerando: a) que este trabalho se configurou como etapa de uma pesquisa; $b$ ) a investigação envolvendo número expressivo de pesquisadores não é objetivo da pesquisa; c) o interesse nas pesquisas em Educação em Ciências Naturais; o campo de investigação deste trabalho foi delimitado a um programa de pós-graduação: Programa de Pós-Graduação em Educação para a Ciência e a Matemática (PCM) da Universidade Estadual de Maringá (UEM), no campus de Maringá. Este é o programa ao qual os autores deste trabalho estão vinculados. Tratase de um dos programas mais antigos na área de Ensino de Ciências e Matemática no Paraná, tendo inciado atividades em 2004 (a maioria dos programas iniciou atividades após 2012), e um dos quatro a ofertar doutorado acadêmico. O PCM oferta capacitação stricto sensu nos níveis de mestrado e doutorado (acadêmicos) e está estruturado em três linhas de pesquisa: "Ensino e Aprendizagem na Educação Científica"; "Formação de Professores de Ciências e Matemática"; "História, Epistemologia e Cultura da Ciência". 
O programa possui um corpo docente que se renovou ao longo dos anos, mas que se identifica pertencente a quatro principais áreas: Ciências Biológicas, Física, Matemática e Química. Alguns docentes orientam apenas em nível de mestrado, enquanto outros orientam nos dois níveis. Tendo em vista as características do programa, considerouse que o campo delimitado apresenta certa representatividade. Buscou-se então, nas dissertações e teses defendidas nesse programa, os indicadores para a proposição de uma resposta (não generalizável) à pergunta.

Um programa de pós-graduação é um campo de investigação importante. Primeiro porque a pós-graduação é um locus natural de pesquisa. Segundo porque estabelece relações entre pesquisadores formadores e pesquisadores em formação. Terceiro porque há um efeito multiplicador, ou seja, egressos de um programa formam novos núcleos de pesquisas. E nesses núcleos, as pesquisas são conduzidas conforme os pressupostos teóricos e metodológicos do programa de pós-graduação. Uma quarta justificativa da importância é a preocupação, em um programa de pós-graduação, com paradigmas de pesquisa atualizados. Outra justificativa é o compartilhamento de experiências entre os pesquisadores de diferentes programas. Resumidamente, uma pós-graduação apresenta ramificação e capilaridade na pesquisa. Por isso os indicadores obtidos desse campo de investigação permitem uma previsão sobre campos mais amplos. Destaca-se também que esses indicadores permitirão discutir: critérios para a constituição de corpus; e o corpus como critério para uma análise e para a qualidade de uma pesquisa.

Portanto o objetivo deste trabalho foi identificar como se apresentam as compreensões e concepções de corpus de análise nas dissertações e teses do PCM. Para alcançar esse objetivo geral, foram elencados alguns objetivos específicos: avaliar a ocorrência do termo corpus; categorizar as ocorrências identificadas; avaliar uma possível polissemia em relação ao termo corpus; identificar convergências e divergências entre as concepções; avaliar compreensões e concepções em função do referencial teórico adotado.

\section{Referencial Teórico}

Para que fossem identificadas e discutidas as compreensões e concepções em dissertações e teses, foi necessário resgatar da literatura pertinente os conceitos de corpus das principais propostas de análise textual. Corpus é termo latino, cujo plural é corpora, que originalmente significa corpo (Glosbe, 2020; Sardinha, 2000). O dicionário Priberam (Informática, 2013), por exemplo, define corpus como "coletânea acerca de um mesmo assunto" e como "conjunto de documentos que servem de base para a descrição ou o estudo de um fenômeno”. O conceito de corpus como coletânea não é recente. Há registros da produção de corpora de citações da Bíblia na Antiguidade e Idade Média (Sardinha, 2000). Porém, a noção de corpus para análise é proveniente da área de Linguística no século XX (Sardinha, 2000). Segundo Aluísio e Almeida (2006), existem duas grandes perspectivas para corpus: uma da Linguística e outra da Linguística de Corpus (LC). Na perspectiva da Linguística, o corpus é um conjunto finito e variado de 
enunciados em uma língua, o qual é tomado como objeto de análise (Sardinha, 2000). Na perspectiva da LC, Sardinha (2000) cita como definição mais completa a elaborada por Sánchez (1995): "Um conjunto de dados lingüísticos [...], sistematizados segundo determinados critérios, [...] dispostos de tal modo que possam ser processados por computador, com a finalidade de propiciar resultados vários e úteis para a descrição e análise". A perspectiva da LC se destaca da Linguística por exigir um material textual processável por computador. Isso é compreensível porque a LC se dedica à análise de corpora extensos, com milhões de palavras (Aluísio \& Almeida, 2006; Sardinha, 2000).

Em um campo com proximidade à Linguística, Eni Orlandi (2015, p. 60) discutiu corpus em uma $\mathrm{AD}$ (neste trabalho, análise de discurso de linha francesa). Constituir o corpus com materiais de análise é uma das primeiras etapas da $\mathrm{AD}$, cujas práticas discursivas podem envolver letra, imagem, som, entre outras. A autora mencionou dois tipos de corpus: o experimental; e o de arquivo. Quando os materiais de análise são produzidos especificamente para a pesquisa, o corpus é dito experimental (ou empírico). Aiub (2012, p. 72) comentou que "[...] os corpora experimentais são baseados no que podemos chamar, a grosso modo, de coleta de dados [...]". Quando são materiais preexistentes, como livros ou documentos, o corpus é dito de arquivo (Caregnato \& Mutti, 2006). Uma outra distinção efetuada por Orlandi refere-se a texto e discurso. O texto "[...] é a unidade que o analista tem diante de si e do qual ele parte", enquanto o discurso "[...] se explicita em suas regularidades pela sua referência a uma ou outra formação discursiva" (Orlandi, 2015, p. 61). Então a autora propôs o corpus como construção de "montagens discursivas que obedecem critérios que decorrem de princípios teóricos da análise de discurso" (Orlandi, 2015, p. 61).

No campo da Educação em Ciências Naturais, Moraes e Galiazzi (2011, p. 16) indicaram que corpus, na ATD, foi uma denominação retirada da obra de Bardin (2011). Eles afirmaram que corpus é um conjunto de documentos, "essencialmente produções textuais" (Moraes, 2003), através do qual toda análise textual se concretiza. Os textos, por sua vez, são produções linguísticas que expressam discursos sobre um fenômeno em um período determinado. Essas produções possuem sentido mais amplo abrangendo “imagens e outras expressões linguísticas" (Moraes \& Galiazzi, 2011, p. 16), podendo ser produzidas para a análise ou selecionadas de documentos previamente existentes. Noções essas que coincidem com o que foi defendido por Orlandi na AD. Moraes assumiu não trabalhar com todo o corpus, mas defendeu a necessidade de definir uma amostra obtida "de um conjunto maior de textos" (Moraes, 2003). Enquanto na Linguística o corpus é o material analisado, para Moraes o material analisado é um excerto do corpus.

Corpus também foi discutido por Bardin (2011) na sua proposição de AC (análise de conteúdo de linha francesa). Para a autora, um corpus "[...] é o conjunto dos documentos tidos em conta para serem submetidos aos procedimentos analíticos" (Bardin, 2011, p. 126). Desse modo, um único documento não constitui um corpus (Bardin, 2011, p. 128). Bardin mencionou que a constituição do corpus "[...] implica, muitas vezes, escolhas, seleções e regras" (Bardin, 2011, p. 126). Resumidamente, 
algumas regras (Bardin, 2011, p. 126) são: a) os documentos selecionados devem ser adequados à análise do fenômeno investigado; b) os documentos devem "[...] obedecer critérios precisos de escolha" (Bardin, 2011, p. 128); c) todos os documentos que atendem o campo e os critérios do corpus devem ser incluídos; d) os documentos devem ser representativos do universo de materiais analisáveis.

$\mathrm{Na}$ abordagem estadunidense de $\mathrm{AC}$, que é a perspectiva fundadora na área (Carlomagno \& Rocha, 2016), Neuendorf (2017, p. 80) estabeleceu uma relação entre arquivo e corpus. Em sua abordagem declaradamente quantitativa, as análises são realizadas sobre arquivos. Arquivo é "[...] uma coleção de mensagens, geralmente bem indexadas" (Neuendorf, 2017, p. 80), armazenadas em formato eletrônico. Nesse caso, uma concordância com a LC pela necessidade do formato digital. O formato eletrônico permite um acesso mais fácil e operações complexas que não eram possíveis antes do uso de computadores. Em áreas das Ciências Humanas e Sociais, os arquivos são frequentemente denominados corpora. Nesse contexto, um corpus é "[...] tipicamente um conjunto de materiais escritos representando uma época e um lugar em particular" (Neuendorf, 2017, p. 81). Neuendorf mencionou que foram estabelecidos padrões para o armazenamento e transferência de textos, que significam critérios para os corpora.

Bauer e Aarts (2015) também discutiram sobre o corpus. Eles apresentaram algumas noções de corpus, como: "coleção de arquivos" (Bauer \& Aarts, 2015, p. 54); e "coleção finita de materiais [...]" (Bauer \& Aarts, 2015, p. 44) determinada de forma arbitrária pelo analista. A primeira noção é concordante com as noções da LC e da AC de linha estadunidense. Para a última noção foi destacado que os materiais devem ser homogêneos, isto é, não devem ser misturados materiais diferentes (texto e imagem, por exemplo) em um mesmo corpus. E esses materiais "exigem um tratamento sistemático" (Bauer \& Aarts, 2015, p. 54). Os autores também sugeriram que a elaboração de um corpus é uma alternativa à coleta de dados, ou seja, sua constituição é funcionalmente equivalente à amostragem. A justificativa é que a amostragem não se aplica a algumas pesquisas qualitativas. Isso se contrapõe àquelas abordagens que propuseram corpus como uma amostra representativa de um determinado universo.

Pode-se afirmar que a maior contribuição para a concepção de corpus de análise é da Linguística, particularmente a LC. E é essa contribuição que determina alguns aspectos comuns entre as abordagens analíticas. Parece haver um acordo: (excetuandose a Linguística) que o material textual não se restringe a texto, mas abrange outros materiais como imagem, áudio e vídeo; da noção de corpus como um conjunto; da necessidade de regras e critérios para a constituição de corpora. Uma diferença entre as abordagens é a natureza do conjunto (que forma um corpus) e as regras para sua constituição. 


\section{Metodologia}

Neste trabalho investigaram-se fenômenos, compreensões e concepções, que não são objetos e não são mensuráveis. A pesquisa não se baseou no armazenamento de dados em variáveis e o posterior processamento dessas. Tampouco a generalização de resultados foi objetivo da pesquisa. Conforme disposto por Hartmut Günther (2006), houve "aceitação explícita da influência de crenças e valores sobre a teoria, sobre a escolha de tópicos de pesquisa, sobre o método e sobre a interpretação de resultados". Esses fatos são suficientes para classificar a pesquisa como qualitativa. E como será exposto adiante, embora qualitativa, esta pesquisa utilizou métodos qualitativos e quantitativos. No intuito de qualificar a pesquisa, de garantir confiabilidade e validade, buscou-se atender questões como as formuladas por Günther (2006 citado por Ollaik \& Ziller, 2012), incluindo: clareza das perguntas de pesquisa; consistência do delineamento de pesquisa; explicitação de paradigmas e construtos analíticos; posição teórica e expectativas dos pesquisadores, entre outras.

A investigação de compreensões e concepções de corpus de análise em dissertações e teses envolveu uma análise textual com o emprego de técnica computacional, o que Neuendorf (2017, p. 146) denominou análise textual auxiliada por computador, "Computer-Aided Text Analysis" (CATA). Pelas técnicas utilizadas, a CATA se tornou zona de convergência de diferentes áreas de investigação, especialmente a Mineração de Textos (MT), a LC e a AC. Em outras palavras, a CATA aplica técnicas comuns a essas áreas de investigação.

A MT pode ser definida como "[...] um conjunto de métodos usados para navegar, organizar, achar e descobrir informação em bases textuais” (Aranha \& Passos, 2006). O objetivo é extrair conhecimento oculto de grandes bases textuais e apresentá-lo de forma coerente e concisa (Bezerra \& Guimarães, 2014; Faro et al., 2012; Patel \& Soni, 2012). Os processos de MT possuem diferentes etapas. Entre as primeiras está o preprocessamento de texto em que as palavras, chamadas types e tokens, são identificadas e separadas de elementos de pontuação, de marcação e de stop words. Types são as palavras distintas, sem repetições, enquanto tokens são as palavras (types) repetidas. Stop words são artigos, pronomes, entre outras palavras consideradas irrelevantes pelo analista na análise (Patel \& Soni, 2012). Em outra etapa as frequências de ocorrência de tokens são calculadas e as coocorrências e contextos determinados (Bezerra \& Guimarães, 2014).

Similarmente à MT, a LC serve-se de técnicas como: identificação e cálculo de frequência de tokens - programas frequenciadores (Mello \& Souza, 2012); processamento estatístico de correlações; identificação de palavras que ocorrem próximas a outra, os collocates (Sardinha, 2011); busca por palavras, expressões e padrões - programas concordanciadores (Aluísio \& Almeida, 2006). Complementando, ao abordar a aplicabilidade da computação na AC, Bardin mencionou as mesmas técnicas supracitadas e afirmou que elas "[... não são exclusivas da análise de conteúdo: a análise literária, a lexicometria, o tratamento documental da informação, por exemplo, também a praticam" (Bardin, 2011, p. 178). 
Há vários programas, softwares, utilizados em CATA (Neuendorf, 2017; Piatetsky-Shapiro \& Mayo, 2019), os quais se diferenciam por objetivos, resultados gerados, exigências de hardware, entre outras características. Neste trabalho utilizou-se um software livre (de código aberto), gratuito e independente de plataforma chamado Voyant Tools (Sinclair \& Rockwell, 2016). O Voyant Tools é um ambiente Web de análise de corpora extensos, com funções de: concordanciador; frequenciador, cálculo de correlações e vínculos entre tokens; identificação de types; representações gráficas, entre outras. O programa possui uma lista de stop words em língua inglesa. Por esse motivo, foi necessária a introdução de um arquivo com stop words em língua portuguesa (Lopes, 2013).

Por meio do Voyant Tools conduziu-se uma análise de corpora. Os corpora foram elaborados a partir de todas as dissertações e teses disponibilizadas no sítio Web do PCM. No sítio foram listadas 203 defesas de mestrado no período de 2006 a 2018 e 65 defesas de tese no período de 2012 a 2018. Justificam-se os períodos pelas primeiras defesas de mestrado e doutorado, respectivamente, no programa, bem como o último ano com defesas registradas no sítio web. Dessas defesas estavam acessíveis os arquivos, em formato PDF, de 196 dissertações e 58 teses. Os arquivos foram convertidos em documentos de texto simples, formato ASCII ("txt"), e agrupados por ano - esse agrupamento é a unitização (Neuendorf, 2017, p. 70). Então cada corpus foi configurado por um arquivo, em formato ASCII ("txt"), contendo todos os documentos de um determinado ano. Geraram-se 13 corpora de dissertações e 7 corpora de teses. Os corpora de dissertações foram processados separadamente dos corpora de teses. Salienta-se que os documentos de dissertações e teses foram as fontes para a constituição dos corpora (os materiais analisáveis) neste trabalho.

$\mathrm{Na}$ investigação das dissertações (o procedimento foi repetido para as teses), todos os corpora foram inseridos e processados simultaneamente no Voyant Tools. Durante o processamento, efetuou-se o cálculo de ocorrência dos types corpus e corpora e suas localizações em contexto, ou Key Word In Context (KWIC). Estabeleceu-se para o contexto, as 30 palavras anteriores e as 30 posteriores ao termo de interesse, que foi denominado unidade de contexto (exemplo na Tabela 1). Cada unidade de contexto foi avaliada, registrando-se o que foi afirmado ou sugerido para o type (corpus ou corpora).

É importante ressaltar que todas as unidades que abordaram corpus como material de análise textual foram seletadas para continuidade da análise, gerando as unidades de análise. Portanto, foram descartadas as unidades de contexto que: abordavam corpus com o sentido de corpo (exemplos "corpus de conhecimento", "corpus teórico"); apresentaram o termo corpus em títulos de capítulos, subcapítulos, figuras, quadros ou tabelas; ou apenas citaram o corpus no processo de análise. Ressalta-se que esse foi um processo de repetidas leituras para certificação de que os itens haviam sido corretamente selecionados. 
Tabela 1. Exemplo de uma unidade de contexto (KWIC)

\begin{tabular}{llll}
\hline corpus & esquerda & Termo & direita \\
\hline \multirow{3}{*}{2006} & análise foram as figuras de retórica. & da pesquisa e a fonte empírica para \\
& $\begin{array}{l}\text { A observação e gravação de três } \\
\text { aulas de Ciências sobre o tema caule } \\
\text { constituíram, juntamente com o livro } \\
\text { didático adotado pela professor/ }\end{array}$ & & $\begin{array}{l}\text { este estudo de caso (Yin, 2002) com } \\
\text { enfoque no exame retórico dos } \\
\text { escola, o }\end{array}$ \\
\end{tabular}

Fonte: elaborado pelos autores, 2020.

Fez-se então uma leitura atenta, rigorosa e criteriosa das unidades de análise, buscando as compreensões e concepções sobre corpus. Quando as unidades se mostraram insuficientes, recorreu-se a trechos mais amplos nos documentos originais. A leitura suscitou temas, os quais foram denominados subcategorias. Para cada subcategoria produziu-se um texto síntese, descrevendo-a e explicitando as ideias em torno de seu tema. É um processo equivalente à "produção de argumentos em torno das categorias" de Moraes (2003). Em seguida agruparam-se as subcategorias em temas mais amplos, que foram denominados categorias de análise. Nesta proposta, as categorias são resultantes da imersão do pesquisador, com suas teorias, na análise. Por isso, tratam-se de categorias emergentes, em acordo com Gamboa (2003) que ratificou a elaboração a posteriori de categorias na pesquisa qualitativa. Os textos sínteses das subcategorias propiciaram a elaboração de sínteses para as categorias, os metatextos. Os metatextos expressam concepções, compreensões, afirmações sobre corpus nas dissertações e teses. Moraes e Galiazzi (2011, p. 32) propuseram que os metatextos representam "um modo de teorização sobre os fenômenos investigados", sendo formados por descrição e interpretação. Segundo esses autores o nível de abstração e teorização é que determinarão um caráter mais descritivo (mais próximo do corpus) ou mais interpretativo (mais afastado "do material original") de um metatexto. São os metatextos que exprimem os indicadores para as compreensões e/ou concepções de pesquisadores sobre corpus em análises textuais.

É necessário destacar a importância do Voyant Tools ao permitir o processamento dos textos completos de dissertações e teses, não apenas fragmentos. Pode-se citar alguns exemplos da literatura que, sem o auxílio de recurso computacional, analisaram fragmentos de documentos. Santos e colaboradores (2017) relataram a análise efetuada por equipe de 10 pesquisadores sobre capítulos de metodologia em 98 dissertações de mestrado. Pedruzzi e colaboradores (2015) ao justificar a análise de 99 resumos de dissertações e teses expressaram: "Mesmo em um grupo formado por dez pesquisadores, ficaria inviável analisarmos tamanho conjunto de trabalhos. [...] Avaliamos que uma média de dez resumos para cada pesquisador permitiria o desenvolvimento de uma pesquisa consistente".

Contribui para a importância do Voyant Tools a sua característica de conjugar 
técnicas de diferentes correntes analíticas, tornando-a recursiva, iterativa, aberta e flexível para ser associada a outras metodologias. Nesse sentido, considera-se a análise realizada neste trabalho como exploratória. Não se trata de exploratória em um sentido superficial, mas uma análise que explora o texto a fim de revelar as informações desconhecidas.

\section{Resultados e Discussões}

\section{Análise dos Corpora de Dissertações}

As 196 dissertações estavam distribuídas por ano conforme apresentado na Tabela 2. No processamento desses corpora o Voyant Tools calculou um total de 9.087.957 de palavras (tokens), dos quais apenas 126.491 foram palavras distintas (types). Estimando uma média de 500 palavras por página, os corpora, reunidos, teriam aproximadamente 18.000 páginas. A relação entre tokens e types apontou que em média as palavras foram repetidas 71 vezes (densidade de vocabulário de 0,014). Contudo, por corpus essa média diminui para aproximadamente 23 repetições.

Não houve ocorrência para o termo corpora nos textos das dissertações e das teses. Por outro lado o termo corpus resultou em 292 unidades de contexto (Tabela 2) entre as dissertações. O corpus com maior número de ocorrências foi o de 2011 com 60 em 11 dissertações. O corpus com menor número de ocorrências foi o de 2007 com 2 em 12 dissertações. Esse resultado pode aguçar a curiosidade e induzir outras perguntas. Porém, a análise concentrada sobre o corpus de 2007, para entender o baixo número de ocorrências, não foi objetivo deste trabalho.

Tabela 2. Distribuição das dissertações e das unidades de contexto e análise por corpus

\begin{tabular}{cccc}
\hline $\begin{array}{c}\text { corpora } \\
\text { (Conjunto de } \\
\text { Dissertações) }\end{array}$ & $\begin{array}{c}\text { Unidades de Contexto } \\
\text { (número de ocorrências } \\
\text { de "corpus") }\end{array}$ & $\begin{array}{c}\text { número de } \\
\text { dissertações por } \\
\text { corpus }\end{array}$ & $\begin{array}{c}\text { Unidades de Análise } \\
\text { (número de ocorrências } \\
\text { selecionadas) }\end{array}$ \\
\hline 2006 & 10 & 16 & 7 \\
2007 & 2 & 12 & 1 \\
2008 & 3 & 16 & 3 \\
2009 & 16 & 21 & 8 \\
2010 & 7 & 19 & 1 \\
2011 & 60 & 11 & 39 \\
2012 & 48 & 14 & 25 \\
2013 & 5 & 12 & 4 \\
2014 & 14 & 13 & 9 \\
2015 & 15 & 12 & 4 \\
2016 & 32 & 17 & 15 \\
2017 & 56 & 16 & 26 \\
2018 & 24 & 17 & $\mathbf{1 5 6}$ \\
\hline Total & $\mathbf{2 9 2}$ & $\mathbf{1 9 6}$ & \\
\hline
\end{tabular}

Fonte: elaborado pelos autores, 2020. 
Após avaliação de todas as unidades de contexto, foram selecionadas 156 (aproximadamente 53\%) como unidades de análise (seleção efetuada segundo os critérios descritos na metodologia). Essas unidades de análise receberam leitura mais cuidadosa, minuciosa, aprofundada para determinação de títulos representativos, ou subcategorias. A maioria das unidades de análise foi associada a uma subcategoria, exceto 3 unidades que foram associadas a 2 subcategorias. Julgou-se não ser possível atribuir somente uma subcategoria nesses 3 casos. Obtiveram-se então 30 subcategorias (Figura 1), as quais foram avaliadas e agrupadas em temas mais amplos, as categorias. Esse agrupamento produziu 4 categorias (a posteriori): caracterização do corpus; definição do corpus; formação do corpus; e operação sobre o corpus. A distribuição das ocorrências do termo corpus entre as categorias foi apresentada em gráfico de setores, Figura 2a.

\begin{tabular}{|c|c|c|}
\hline $\begin{array}{l}\text { Subcategorias } \\
\text { Corpora de Dissertações }\end{array}$ & $\begin{array}{l}\text { Subcategorias } \\
\text { Corpora de Teses }\end{array}$ & $\begin{array}{l}\text { Categorias } \\
\text { resultantes }\end{array}$ \\
\hline $\begin{array}{l}\text { corpus como um arquivo; } \\
\text { corpus é um arquivo com "formulações } \\
\text { linguísticas" escritas e orais; } \\
\text { corpus possui "categorias (de análise)"; } \\
\text { corpus possui "elementos para 'ancorar' } \\
\text { resultados"; } \\
\text { corpus possui "traços empíricos do discurso"; } \\
\text { corpus possui "unidades de análise"; } \\
\text { o corpus possui relações com discursos; } \\
\text { o corpus está relacionado ao universo } \\
\text { estudado; }\end{array}$ & $\begin{array}{l}\text { as teorias do pesquisador } \\
\text { determinam o corpus; } \\
\text { corpus possui grande extensão; }\end{array}$ & $\begin{array}{l}\text { caracterização } \\
\text { do corpus }\end{array}$ \\
\hline $\begin{array}{l}\text { corpus definido como conjunto de } \\
\text { documentos; } \\
\text { corpus definido como conjunto de textos; } \\
\text { corpus definido como material coletado; } \\
\text { corpus definido como material contendo } \\
\text { "algo"; } \\
\text { corpus definido como material contendo } \\
\text { informação; } \\
\text { corpus definido como material contendo } \\
\text { sentidos; } \\
\text { corpus definido como material para análise; } \\
\text { corpus definido como os dados da pesquisa; } \\
\text { corpus definido como textos examináveis; } \\
\text { corpus definido como uma ação; }\end{array}$ & $\begin{array}{l}\text { corpus definido como conjunto de } \\
\text { documentos; } \\
\text { corpus definido como conjunto de } \\
\text { textos; } \\
\text { corpus definido como material } \\
\text { concreto; } \\
\text { corpus definido como material } \\
\text { empírico; } \\
\text { corpus definido como produções } \\
\text { textuais; } \\
\text { corpus definido como produções } \\
\text { linguísticas sobre um fenômeno; } \\
\text { corpus definido como material para } \\
\text { análise; }\end{array}$ & $\begin{array}{l}\text { definição do } \\
\text { corpus }\end{array}$ \\
\hline
\end{tabular}

Figura 1. Subcategorias de análise para os corpora de dissertações e teses e categorias resultantes (continua) 


\begin{tabular}{|c|c|c|}
\hline $\begin{array}{l}\text { Subcategorias } \\
\text { Corpora de Dissertações }\end{array}$ & \begin{tabular}{|l|} 
Subcategorias \\
Corpora de Teses
\end{tabular} & $\begin{array}{l}\text { Categorias } \\
\text { resultantes }\end{array}$ \\
\hline $\begin{array}{l}\text { corpus formado por dados; } \\
\text { corpus formado por diferentes materiais e/ou } \\
\text { instrumentos de coleta de dados; } \\
\text { corpus formado por um único tipo de } \\
\text { material; } \\
\text { corpus formado por materiais/produções } \\
\text { textuais; } \\
\text { indivíduos compondo o corpus; }\end{array}$ & $\begin{array}{l}\text { corpus formado por dados; } \\
\text { corpus formado por diferentes } \\
\text { materiais e/ou instrumentos de } \\
\text { coleta de dados; } \\
\text { corpus formado por um único tipo } \\
\text { de material; }\end{array}$ & $\begin{array}{l}\text { formação do } \\
\text { corpus }\end{array}$ \\
\hline $\begin{array}{l}\text { corpus fragmentado para análise; } \\
\text { a configuração do trabalho com o corpus; } \\
\text { a elaboração do corpus deve respeitar regras; } \\
\text { corpus opcionalmente matematizado; } \\
\text { corpus, material que é lido para identificação } \\
\text { de "unidades de registro"; } \\
\text { corpus, material que precisa do envolvimento } \\
\text { dos pesquisadores; } \\
\text { corpus, material utilizado para definição de } \\
\text { categorias; }\end{array}$ & corpus fragmentado para análise. & $\begin{array}{l}\text { operação } \\
\text { sobre o } \\
\text { corpus }\end{array}$ \\
\hline
\end{tabular}

Figura 1. Subcategorias de análise para os corpora de dissertações e teses e categorias resultantes (continuação)

Fonte: elaborado pelos autores, 2020.
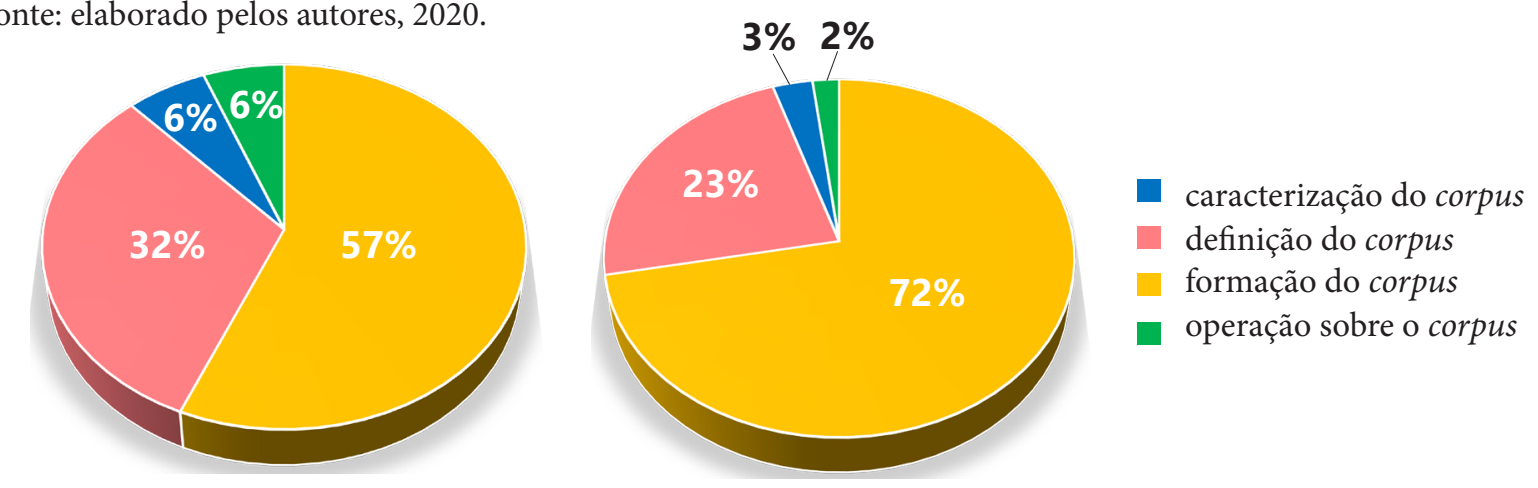

Figura 2. Porcentagem de ocorrências do termo corpus por categorias emergentes em: (a) dissertações; e (b) teses

Fonte: elaborado pelos autores, 2020.

No gráfico os porcentuais foram arredondados para números inteiros, por esse motivo o somatório atinge $101 \%$. Percebe-se que a maioria das ocorrências versou sobre a formação de um corpus, contrastando uma minoria que abordou a caracterização de corpus. Esse resultado indica uma preocupação dos pesquisadores com os constituintes 
de um corpus e talvez pouca atenção aos critérios para a constituição.

Como parte da análise, foram gerados metatextos para as categorias elencadas. Nas análises de dissertações e de teses emergiram as mesmas categorias. Por esse motivo os metatextos elaborados na análise das dissertações foram mesclados com os metatextos elaborados na análise das teses. Essas sínteses gerais estão presentes no final desta seção de resultados e discussões.

\section{Análise dos Corpora de Teses}

As 58 teses estavam distribuídas por ano conforme apresentado na Tabela 4. O Voyant Tools calculou um total de 4.349.636 tokens, 85.697 types e uma densidade de vocabulário de 0,02 (média de repetição de 50 vezes). Por corpus a média de repetição diminui para aproximadamente 21 vezes, valor comparável ao obtido para as dissertações.

Tabela 4. Distribuição das teses e das unidades de contexto e análise por corpus

\begin{tabular}{cccc}
\hline $\begin{array}{c}\text { Corpora } \\
\text { (Conjunto de Teses) }\end{array}$ & $\begin{array}{c}\text { Unidades de Contexto } \\
\text { (número de ocorrências } \\
\text { de “corpus") }\end{array}$ & $\begin{array}{c}\text { número de teses } \\
\text { por corpus }\end{array}$ & $\begin{array}{c}\text { Unidades de Análise } \\
\text { (número de ocorrências } \\
\text { selecionadas) }\end{array}$ \\
\hline 2012 & 6 & 2 & 1 \\
2013 & 41 & 13 & 17 \\
2014 & 10 & 7 & 3 \\
2015 & 26 & 11 & 9 \\
2016 & 40 & 12 & 14 \\
2017 & 20 & 5 & 5 \\
2018 & 31 & 8 & 12 \\
\hline Total & 174 & 58 & 61 \\
\hline
\end{tabular}

Fonte: elaborado pelos autores, 2020.

O termo corpus ocorreu em 174 unidades de contexto (Tabela 4) entre as teses. O corpus com maior número de ocorrências foi o de 2016 com 40 em 12 teses. A avaliação das unidades de contexto gerou 61 unidades de análise (35\% das unidades de contexto). $\mathrm{Na}$ sequência da análise obtiveram-se 13 subcategorias. Também registraram-se 3 unidades de análise associadas a 2 subcategorias. Das 13 subcategorias para os corpora de teses, apenas 5 foram coincidentes com aquelas para os corpora de dissertações: corpus definido como material para análise; corpus formado por dados; corpus formado por diferentes materiais e/ou instrumentos de coleta de dados; corpus formado por um único tipo de material; corpus fragmentado para análise. Porém, essas subcategorias foram organizadas nas mesmas 4 categorias definidas anteriormente. A distribuição das ocorrências do termo corpus entre as categorias foi apresentada na Fig. 2b. O gráfico da Fig. 2 b apresenta o mesmo perfil do gráfico da Fig 2a, confirmando a indicação de uma preocupação com constituintes de corpus e pouca atenção aos critérios de constituição. 


\section{Metatextos das Categorias}

Neste trabalho foram elaborados metatextos de caráter mais descritivo. Contudo, após a apresentação de cada metatexto, foi incluído um exercício interpretativo com "intuições e entendimentos atingidos a partir da impregnação intensa [...]" (Moraes \& Galiazzi, 2011, p. 37) com os corpora analisados. Conforme mencionado previamente, os metatextos na análise dos corpora de dissertações foram elaborados independentemente dos metatextos na análise dos corpora de teses e só mesclados ao final.

A primeira categoria resgatada para a discussão é Caracterização do Corpus. Esta é a categoria em que as unidades de análise apresentaram alguma caracterização do corpus. Duas propostas analíticas destacaram-se como referências entre os trabalhos envolvidos pelas ocorrências: a AD de linha francesa (Moreira, 2012; Orlandi, 2015) e a ATD de Moraes e Galiazzi (2011). Uma primeira característica é que um corpus reflete as teorias que orientam e acompanham a pesquisa do analista. O corpus é elaborado e organizado em acordo com as orientações dessas teorias. Entre as unidades de análise identificou-se também o corpus com característica de um arquivo com materialidade e composto por "formulações linguísticas", na forma escrita e/ou oral, produzidas por sujeitos de uma pesquisa. O corpus possui um "dizer" que é constituído pela relação com outros discursos, bem como possui "traços empíricos do discurso" de um indivíduo ou grupo social. Esses traços são identificados pelo analista de discurso quando reorganiza o corpus. O corpus também possui elementos, que extraídos, permitem ao pesquisador "ancorar" resultados em uma realidade empírica. Do corpus são obtidas unidades de análise, as quais acompanham categorias de análise. E as categorias são obtidas da imersão do pesquisador sobre o material de análise e do agrupamento de elementos de significação semelhantes. Além de unidades de análise uma categoria é acompanhada por um metatexto. Outra característica para o corpus é sua relação com o universo estudado, isto é, "a constituição do corpus diz respeito ao universo estudado em sua totalidade e a formulação e reformulação de hipóteses e objetivos". Uma última característica, identificada em alguns trabalhos que utilizaram a ATD, é que um corpus possui grande extensão e por isso o analista trabalha com parte do corpus.

Moraes e Galiazzi (2011, p. 39) sugeriram que "os metatextos não devem ser entendidos como modos de expressar algo já existente nos textos, mas como construções do pesquisador com intenso envolvimento de sua parte". Assim, com base na sugestão desses autores efetuou-se um exercício de reflexão sobre o metatexto elaborado. Inicia-se a reflexão com a ideia de corpus como arquivo. O corpus como arquivo é um espaço em que se mantém um conjunto de documentos ou materiais. Um arquivo pode ser "aberto", permitindo que sejam inseridos, removidos ou acessados os documentos contidos nele e considerando-se as tecnologias de informação digitais, pode-se propor um corpus como arquivo eletrônico. Por outro lado, Aiub (2012), citando Pêcheux, colocou que "arquivo é ' [...] entendido, no sentido amplo, de campo de documentos pertinentes e disponíveis sobre uma questão' [...] o arquivo é [...] organizado por umaleitura"; o corpuséconstruído a partir da leitura de arquivos. O corpus como material textual é elaborado a partir de 
um código linguístico. Caso seja considerada a possibilidade de um material textual de origem visual, deve-se considerar que esse material seja transposto do objeto visual para um com os sinais e estrutura de um código linguístico. A compreensão da mensagem deve depender do reconhecimento desse código e sua adequada interpretação. As mensagens fazem parte dos discursos registrados em um corpus. Além das mensagens, um corpus apresenta elementos de pensamento, de conhecimento, de concepções, de crenças, de história, entre outros, daqueles que emitiram um ou mais discursos. Esses elementos é que devem permitir que os resultados da análise textual sejam conectados à "realidade empírica" (o contexto, o espaço e o período daquilo que é investigado). Isso é uma forma de garantir confiabilidade e validade da análise (Moraes, 2003). Para o analista, explorar um corpus passa por teorizações, por leituras imersivas e exaustivas, por formulação de perguntas e hipóteses, por fragmentação do material textual, entre outros. E é na fragmentação que o analista pode selecionar unidades relacionadas a assuntos ou temáticas, as quais podem ser agrupadas em temas mais amplos denominados posteriormente de categorias (categorias que emergem do corpus a partir do processo de análise). Nas unidades de análise não foi encontrada determinação, ou mensuração, do que seja um corpus de "grande extensão".

A segunda categoria resgatada é Definição do Corpus. A categoria reúne as unidades de análise que apresentaram uma definição para corpus. Percebeu-se que as compreensões de corpus entre as dissertações foram influenciadas predominantemente por duas propostas analíticas: a AC de Bardin (2011) e a ATD. A proposta de AD destacou-se entre as teses. Nas unidades de análise, de um modo geral e independente da proposta analítica, o corpus é um material produzido ou selecionado por um pesquisador para sua pesquisa. Adicionalmente corpus foi definido como produções textuais, um conjunto de documentos ou conjunto de textos. As produções textuais também são reconhecidas como produções linguísticas que abordam, ou referem-se, a um ou mais fenômenos de um determinado contexto e período. Um corpus é lido, examinado e analisado, "por impregnação intensa", segundo critérios estabelecidos pelo pesquisador em um processo que envolve procedimentos e técnicas analíticas. Em alguns trabalhos baseados na ATD destacaram-se três compreensões para corpus: "conjunto de documentos que representa as informações da pesquisa" (e as informações podem auxiliar na elaboração de categorias de análise); material do qual são extraídos sentidos no processo de análise; material sobre o qual a análise textual se concretiza. Nas unidades de análise em que corpus foi definido apenas como material coletado para ser estudado na pesquisa, não há identificação de seu tipo (texto, áudio, imagem, entre outros). Quando definido o tipo texto, o corpus foi compreendido como o conjunto de dados da pesquisa, tendo surgido inclusive a expressão "corpus de dados". E o conjunto de documentos contendo dados é selecionado de forma a garantir resultados que sejam confiáveis. Dependendo da proposta metodológica de análise (ATD, AD) o corpus será reconhecido como "material concreto" ou empírico, isto é, o material contendo os dados obtidos ou coletados de instrumentos, registros, entre outras fontes. Em uma unidade 
de análise encontrou-se uma definição totalmente divergente da ideia de corpus como um material. Nela o corpus consistiu na aplicação de uma oficina, ou seja, uma ação.

No metatexto a impregnação intensa pode ser entendida como o processo em que o analista se debruça concentrada e intensamente sobre o corpus, intuindo, inferindo, deduzindo, identificando categorias, entre outros. Outra ideia destacada diz respeito aos sentidos extraídos de um corpus. Esses podem ser as ideias que não estão explícitas, mas que são identificadas através das interpretações, intuições e deduções do analista. Por último, a compreensão de corpus como conjunto que representa as informações de pesquisa, oriunda de uma dissertação de 2012 que usou ATD, se contrapõe a uma citação a Guilhaumou e Maldidier (1997) em uma das dissertações de 2011, que um arquivo "não pode ser traduzido como um documento do qual se retiram informações".

A terceira categoria é Formação do Corpus. Esta categoria reúne as unidades de análise que abordaram como um corpus é formado. Na maioria dessas unidades verificase que o corpus é formado por um ou mais materiais, com ou sem especificação destes. Em três unidades de análise surgiu uma indicação divergente e incomum: corpus composto por indivíduos (exemplo “[...] dos bolsistas constituintes do corpus de pesquisa [...]”). Houve indicação de corpus como matéria-prima da pesquisa e constituído de produções textuais (em referência a ATD), bem como indicação de corpus formado por dados (não definido como conjunto de dados, nem formado exclusivamente por esses). Destaca-se em uma unidade de análise a menção "corpus de dados". Em outra unidade a afirmação que os textos que compõem o corpus são os dados propriamente ditos e que "[...] todo dado torna-se informação a partir de uma teoria, [...] 'nada é realmente dado', mas tudo é construído". A maioria das unidades de análise aponta para corpus formado por um ou por diferentes tipos de materiais. Em algumas situações não há diferenciação entre os instrumentos de coleta de dados e os dados coletados através destes.

Dentre os materiais constituintes de corpus exemplificam-se: livros didáticos, capítulos de livros didáticos, registros de observação, aulas, gravação de aulas, atas de eventos, registros em jornais, filmagens, documentos históricos, atividade prática (a atividade ou um registro da atividade?), entrevistas, questionários, transcrições de entrevistas, transcrições de questionários, diários de campos, depoimentos, levantamento bibliográfico, referências bibliográficas, análise documental, transcrições de aulas, excertos de discussões, análise epistemológica, avaliação formal, matrizes de avaliação, textos de apoio, planejamentos didáticos, áudios de cursos, referências bibliográficas, referenciais teóricos, relatos de experiência, relatos, artigos, revistas, produções didáticopedagógicas, capítulos de livros didáticos, documentos, dissertações e tese (dissertações e tese foram considerados um mesmo tipo de material), narrativas, diários, escritos de Leonardo da Vinci, cartazes (análise de imagens), atividade experimental, atividades de uma sequência didática. Em algumas unidades de análise os autores descreveram um corpus formado por um único tipo de material, por exemplo corpus constituído por transcrições de entrevistas. Em outras unidades de análise os autores descreveram um corpus formado por mais de um tipo (diferente) de material, por exemplo "o 
corpus constitui todos os dados coletados: as respostas dos questionários, as narrativas produzidas e as transcrições das entrevistas realizadas com os estudantes, além dos documentos do curso, como o PPP [...]”.

Uma primeira reflexão sobre o metatexto desta categoria é que dados constituem o material que é processado para gerar informação. Se o analista extrai do corpus excertos para sua análise, significa que esses são os dados, não o corpus integralmente. Nessa situação, os dados não abrangem, necessariamente, a totalidade dos materiais textuais que compõem um corpus. Uma segunda reflexão trata do corpus formado por diferentes tipos de materiais, indicando a falta de homogeneidade e de distinção entre corpus e corpora. Isso pode justificar, parcialmente, a não ocorrência do type corpora nas dissertações e teses. A última reflexão trata de corpus constituído por indivíduos. As três unidades de análise que apresentaram a compreensão de corpus formado por indivíduos foram extraídas de duas dissertações de mestrado, uma de 2016 e outra de 2018, envolvendo pesquisadores de um mesmo grupo de pesquisa. Nas duas dissertações foram propostos corpora formados por indivíduos (bolsistas de Programa Institucional de Bolsa de Iniciação à Docência) e por materiais textuais (diários e respostas de questionários, respectivamente) - corpus formado por diferentes materiais. Adicionalmente, a dissertação de 2018 é a origem da definição de corpus como aplicação de oficina, comentada na categoria Definição de Corpus. É preciso lembrar que todos os referenciais tratam de materiais textuais como constituintes de corpus, pois a análise é textual. E em acordo com a categoria Operação sobre o Corpus, na análise efetuamse operações sobre um corpus (o corpus não é uma operação/ação). Um indivíduo não é um material textual, nem é submetido a uma operação. Contudo ele pode ser fonte de materiais textuais quando externaliza algo por diferentes linguagens. Tratar um indivíduo como componente de um corpus é incompatível com os referenciais e denota incompreensão do conceito de corpus de análise.

A última categoria formada foi Operação sobre o Corpus. Esta categoria reúne unidades de análise que mencionam algum tipo de operação sobre o corpus. Tratam-se de operações para a elaboração do corpus ou de análise do corpus. Para a elaboração do corpus devem ser seguidas regras, as quais agregarão confiabilidade e validade à análise. Nesse caso foram citadas algumas das regras que constam na obra Análise de Conteúdo de Bardin (2011): regra da exaustividade, regra da amostragem, regra da homogeneidade, regra da pertinência. $\mathrm{Na}$ análise o analista envolve-se com o corpus, o lê intensivamente para compreendê-lo e identificar unidades de registro. De forma similar, em uma tese foi mencionada a necessidade de fragmentação do corpus no processo de análise, para permitir o destaque de trechos importantes denominados unidades constituintes. Essa fragmentação é efetuada a partir de critérios estabelecidos pelo analista, em acordo com teorias e metodologias por ele escolhidas. No processo de leitura intensiva o analista também separa excertos (recortes), e identifica categorias e subcategorias. Uma unidade de análise, citando Bardin (2011), colocou que "A categorização é uma operação de classificação de elementos constitutivos de um conjunto [...]". Esse envolvimento com o 
corpus ocorre em função da relação entre a teoria e a análise (uma referência a proposta de AD), das características dos dados, dos objetivos do analista e das questões por ele formuladas. Em uma unidade de análise foi destacada que a aplicação de procedimentos matemáticos no processo de análise é uma opção do analista, na qual se supera a mera quantificação e busca-se a compreensão de regularidades do discurso no corpus.

Do metatexto pode-se colocar que em uma pesquisa existem ações que são efetuadas sobre o corpus, as quais podem ocorrer no processo de elaboração ou de análise do corpus. A leitura, por exemplo, é uma ação que não produz um efeito sobre um corpus, não o altera. Uma fragmentação, por outro lado, é uma operação sobre o corpus. O envolvimento do analista com o corpus implica um processo intenso, metódico, recursivo de leitura, de compreensão, de apreensão, de interpretação, entre outros. E nesse envolvimento com o corpus o analista pode combinar procedimentos quantitativos e qualitativos, mantendo a característica qualitativa da análise e desviandose do dualismo mencionado por Gamboa (2003). Nesse sentido, a unidade de análise que destacou os procedimentos matemáticos é importante por indicar uma dissertação que empregou exame estatístico e $\mathrm{AD}$, exemplificando assim a superação do dualismo pesquisa qualitativa e quantitativa.

Em uma avaliação global, confirmaram-se três referenciais majoritariamente utilizados pelos pesquisadores do PCM: a obra de Laurence Bardin; as obras de Eni Orlandi; a obra de Roque Moraes e Maria do C. Galiazzi. As menções sobre corpus de análise nos documentos são quase reproduções das obras citadas, sem uma reflexão sobre as discussões promovidas pelos autores dos referenciais. A impressão provocada é que houve, de modo geral, uma aplicação sem uma apropriação epistemológica das abordagens analíticas. Ao mesmo tempo em que as concepções convergem ao reproduzir os mesmos referenciais, elas divergem por uma desarmonia com esses referenciais. A divergência foi flagrante em concepções como: corpus composto por indivíduos; corpus como aplicação de uma oficina; corpus formado por instrumentos de coleta de dados (ao invés dos dados coletados com esses instrumentos).

Entre alguns dos referenciais utilizados neste trabalho (Bardin, 2011; Bauer \& Aarts, 2015; Orlandi, 2015; Sánchez, 1995) há o apontamento de necessidade de critérios a serem obedecidos na construção de um corpus. Retornando às categorias obtidas, verifica-se que não houve a apresentação de critérios detalhados, claros e específicos (em acordo com a metodologia analítica adotada) utilizados na elaboração dos corpora. Apenas registrou-se uma menção à necessidade de regras, particularmente aquelas propostas por Bardin (2011, p. 126) que têm caráter mais amplo. A incerteza em relação a critérios é intensificada pelo exposto no metatexto da categoria formação do corpus: corpus constituído por diferentes tipos de materiais. Isso conflita com o critério apresentado por Bauer e Aarts (2015) de homogeneidade de materiais em um corpus. Materiais diferentes são organizados, preparados e tratados de forma distinta. Por exemplo, a análise de uma imagem não segue o mesmo protocolo da análise de uma entrevista em áudio (Bauer \& Gaskell, 2015). 
De fato não se verificou nas unidades de análise o uso, ou resgate, de outros referenciais teóricos, como a LC, ou especialmente a linha estadunidense de AC. Tais referenciais aprimorariam concepções, compreensões sobre as metodologias adotadas e cuidados na constituição de corpus. Seriam evitadas, por exemplo, afirmações de corpus formado por diferentes materiais, ou confusões entre dados e informações.

\section{Conclusões e Implicações}

Pode-se colocar que, em relação ao universo investigado, as menções de corpus (para uma análise textual) estão vinculadas às metodologias analíticas adotadas, majoritariamente a AC (francesa), a AD (francesa) e a ATD. Apesar deste vínculo, foram evidenciadas fragilidades nas compreensões e concepções do que deve ser um corpus e de como ele deve ser elaborado e processado. De um modo geral, corpus foi considerado um mero conjunto, algo reunido para uma pesquisa. Essas fragilidades estão relacionadas a dois afastamentos. O primeiro é o afastamento das concepções sobre corpus em relação aos referenciais adotados. Os referenciais foram citados, reproduzidos, mas não foram apropriados adequadamente. O segundo é o afastamento entre os referenciais adotados e destes em relação à Linguística. Não se identificou uma caracterização de corpus comum e independente das metodologias e referenciais utilizados. E a noção de corpus originária da Linguística parece ter sido perdida. Esses apontamentos foram, de certo modo, corroborados pelas bancas avaliadoras das dissertações e teses. Isso não significa omissão, mas provavelmente uma naturalização do uso do termo corpus sem um aprofundamento conceitual.

Os resultados obtidos determinam algumas implicações para as pesquisas na área de Educação em Ciências Naturais. Por exemplo, há um indicativo nos resultados que os pesquisadores atentaram pouco a critérios para elaboração de corpora. Entretanto, um corpus válido (e que confira validade à análise) precisa ser elaborado em acordo com critérios bem definidos. Mesmo que as metodologias analíticas apresentem concepções de corpus distintas, eles são necessários. Aliás, se compreende possível estabelecer alguns critérios comuns a tais metodologias. Um exemplo é a garantia de disponibilidade e de acessibilidade a outros pesquisadores. Sugere-se nesse caso a geração de arquivos eletrônicos, seguindo padrões para formato, armazenamento e transferência. Outro exemplo está relacionado à homogeneidade de um corpus, isto é, constituição por um único tipo de material. Julga-se importante que materiais diferentes sejam sistematizados em corpora separados. Em razão da necessidade de critérios, pretende-se em trabalho subsequente, apresentar um conjunto para a elaboração de corpora que poderá ser aplicado em várias metodologias analíticas na pesquisa em Educação em Ciências. Ressalta-se que esse conjunto de critérios poderá ratificar o corpus como elemento que estabelece aproximação entre as diferentes metodologias de análise.

Um corpus pode ser considerado uma fonte de dados sistematizados em uma análise textual, independentemente se todo o seu conteúdo ou apenas excertos serão analisados. A análise textual, propriamente dita, é iniciada com um corpus e efetuada 
sobre este. Em princípio os dados representam um certo fenômeno em um determinado contexto e período, por isso esses dados permitem ao analista conectar resultados de uma análise a uma realidade empírica. Isso é importante, mas é insuficiente para garantir confiabilidade e validade à análise. $\mathrm{O}$ corpus como fonte de dados precisa estar disponível e acessível a outros pesquisadores, o que se configura em outro requisito para confiabilidade e validade. Defende-se, a partir dos aspectos apresentados e de referenciais como Bauer e Gaskell (2015), que se considere o corpus como um critério para a confiabilidade e validade de uma análise textual. Se um pesquisador elege um conjunto de materiais textuais para analisá-los, tornar-se-á fundamental a constituição de um corpus ou corpora.

Outro assunto importante é a polissemia do termo corpus. Surgiram nas unidades de contexto expressões que não se relacionam à análise textual, por exemplo: "corpus do conhecimento físico", "corpus geográfico", "corpus de saberes", "corpus teórico", "corpus filosófico", entre outras. Ou seja, alguns documentos utilizaram o termo corpus com mais de um sentido. Para minimizar esse problema, sugere-se a expressão "corpus de análise" quando a referência for ao material elaborado para uma análise textual. Complementando a sugestão, seria interessante também que pesquisadores em Educação em Ciências consultassem referenciais da Linguística, especialmente a LC, para melhor compreender a noção de corpus de análise.

Ampliando as considerações sobre corpus de análise, salienta-se que neste trabalho foram produzidos corpora de análise extensos. $\mathrm{O}$ uso de recurso computacional foi essencial para a investigação com tais corpora. Em realidade, além de identificar as compreensões sobre corpus, procurou-se mostrar a viabilidade de um processo analítico que concilia CATA, análise categorial e elaboração de metatextos. É um processo que tem potencial para ampliar os horizontes de pesquisa qualitativa em Educação em Ciências. A primeira razão é a possibilidade de analisar corpora de análise extensos e não apenas documentos fragmentados ou limitados. A segunda razão é que um pesquisador pode combinar diferentes programas, qualitativos e/ou quantitativos, para robustecer o processo de análise. As limitações estarão primordialmente relacionadas às capacidades de processamento e armazenamento. Enquanto as dificuldades estarão relacionadas ao nível de engajamento e de capacitação de um pesquisador para usar os recursos computacionais de análise textual.

Complementando, alguns resultados gerados pelo programa Voyant Tools instigam análises que não foram escopo deste trabalho (exemplo, o porquê apenas duas ocorrências do termo corpus entre as dissertações de 2007). Tais análises podem ser objeto de investigação em outras propostas de pesquisa, quer estejam em desenvolvimento, quer sejam futuras. Para isso, os dados que suportam os resultados deste estudo, arquivos de dissertações e teses, foram derivados dos seguintes recursos disponíveis em domínio público: vínculo Produções no sítio web do PCM; <http://www.pcm.uem.br/ dissertacoes $>$; <http://www.pcm.uem.br/teses $>$.

Por fim, os resultados apresentados não são generalizáveis. Mas em acordo ao 
que foi mencionado inicialmente neste trabalho, é possível predizer que em um universo mais abrangente de pesquisadores da área de Educação em Ciências Naturais, deverão ser verificadas as mesmas compreensões e concepções. Isto exige desses pesquisadores uma autoavaliação e revisão de fundamentos teóricos e metodológicos que orientam suas pesquisas.

\section{Referências}

Aiub, G. F. (2012). Arquivo em Análise do Discurso: Uma breve discussão sobre a trajetória teórico-metodológica do analista. Leitura, 2(50), 61-82. https://doi.org/10/ ggxxm3

Aluísio, S. M., \& Almeida, G. M. de B. (2006). O que é e como se constrói um corpus? Lições aprendidas na compilação de vários corpora para pesquisa linguística. Calidoscópio, 4(3), 156-178. https://doi.org/10.4013/6002

Aranha, C., \& Passos, E. (2006). A Tecnologia de Mineração de Textos. Revista Eletrônica de Sistemas de Informação, 5(2), 1-8. https://doi.org/10/ggmkf7

Bardin, L. (2011). Análise de Conteúdo (L. A. Reto \& A. Pinheiro, Trads.; 1a ed). Edições 70 .

Bauer, M. W., \& Aarts, B. (2015). A construção do corpus: Um princípio para a coleta de dados qualitativos. In M. W. Bauer \& G. Gaskell (Orgs.), Pesquisa qualitativa com texto, imagem e som: Um manual prático (13a ed, p. 39-63). Vozes.

Bauer, M. W., \& Gaskell, G. (Orgs.). (2015). Pesquisa qualitativa com texto, imagem e som: Um manual prático (13a ed). Vozes.

Bezerra, C. A., \& Guimarães, A. J. R. (2014). Mineração de texto aplicada às publicações científicas sobre gestão do conhecimento no período de 2003 a 2012. Perspectivas em Ciência da Informação, 19(2), 131-146. https://doi.org/10/ggmk7q

Caregnato, R. C. A., \& Mutti, R. (2006). Pesquisa qualitativa: Análise de discurso versus análise de conteúdo. Texto \& Contexto - Enfermagem, 15(4), 679-684. https://doi.org/10/ dkczmh

Carlomagno, M. C., \& Rocha, L. C. da. (2016). Como Criar e Classificar Categorias para Fazer Análise de Conteúdo: Uma Questão Metodológica. Revista Eletrônica de Ciência Política, 7(1), 173-188. https://doi.org/10/gd7gbz

Chrysostomo, T. da S., \& Messeder, J. C. (2017). Uso Da Publicidade Televisiva na Sala de Aula: Percepções e Contribuições de Acadêmicos de Licenciatura em Química. Revista Areté| Revista Amazônica de Ensino de Ciências, 10(22), 281-293. http://periodicos.uea. edu.br/index.php/arete/article/view/650

Faro, A., Giordano, D., \& Spampinato, C. (2012). Combining literature text mining with microarray data: Advances for system biology modeling. Briefings in Bioinformatics, 13(1), 61-82. https://doi.org/10/dq79ks 
Gamboa, S. A. S. (2003). Pesquisa Qualitativa: Superando tecnicismos e falsos dualismos. Revista Contrapontos, 3(3), 393-405. https://siaiap32.univali.br/seer/index.php/rc/ article/view/735

Glosbe. (2020). Corpus em Português - Latim-Português Dicionário. In Glosbe dicionário [em linha]. https://pt.glosbe.com/la/pt/corpus

Günther, H. (2006). Pesquisa qualitativa versus pesquisa quantitativa: Esta é a questão? Psicologia: Teoria e Pesquisa, 22(2), 201-209. https://doi.org/10/db5743

Informática, P. (2013). Definição de corpus no Dicionário Priberam da Língua Portuguesa, o dicionário online de português contemporâneo. In Dicionário Priberam da Língua Portuguesa [em linha]. https://dicionario.priberam.org/corpus

Lopes, A. (2013). Portuguese stop words. GitHub Gist. https:/gist.github.com/ alopes/5358189

Mello, H. R. de, \& Souza, R. R. (2012). A linguagem da ciência: Prospecção de dados baseados em corpora. STIS Seminários Teóricos Interdisciplinares do SEMIOTEC Cadernos Didáticos e Anais, 1(1), 19p. http://www.periodicos.letras.ufmg.br/index.php/ stis/article/view/2115

Moraes, R. (2003). Uma tempestade de luz: A compreensão possibilitada pela análise textual discursiva. Ciência \& Educação (Bauru), 9(2), 191-211. https://doi.org/10/ dv5 vc4

Moraes, R., \& Galiazzi, M. do C. (2011). Análise Textual Discursiva (2a ed). Editora Unijuí.

Moreira, L. A. L. (2012). Análise do Discurso no Brasil: Reflexões acerca de sua construção teórico-metodológica. Leitura, 2(50), 109-133. https://doi.org/10/ggxxts

Neuendorf, K. A. (2017). The content analysis guidebook (Second edition). SAGE.

Oliveira, E., Ens, R. T., Andrade, D. B. S. F., \& Muss, C. R. (2003). Análise de Conteúdo e Pesquisa na Área da Educação. Revista Diálogo Educacional, 4(9), 11. https://doi.org/10/ ggkxdw

Ollaik, L. G., \& Ziller, H. M. (2012). Concepções de validade em pesquisas qualitativas. Educação e Pesquisa, 38(1), 229-242. https://doi.org/10/gfwgvp

Orlandi, E. P. (2015). Análise de discurso: Princípios \& procedimentos (12a ed). Pontes.

Patel, F. N., \& Soni, N. R. (2012). Text mining: A Brief survey. International Journal of Advanced Computer Research, 2(4), 234-239. https://pdfs.semanticscholar. org/11c4/6d00a0e136e8e4e27aa15fbb8c9111cdee75.pdf

Pedruzzi, A. das N., Schmidt, E. B., Galiazzi, M. do C., \& Podewils, T. L. (2015). Análise Textual Discursiva: Os movimentos da metodologia de pesquisa. Atos de Pesquisa em Educação, 10(2), 584-604. https://doi.org/10/ggkxv2 
Piatetsky-Shapiro, G., \& Mayo, M. (2019). Text Analysis, Text Mining, and Information Retrieval Software. KDnuggets. https://www.kdnuggets.com/software-for-data-mininganalytics-data-science-and-knowledge-discover/text-analysis-text-mining-andinformation-retrieval-software/

Pinhão, F., \& Martins, I. (2009). A Análise do Discurso e a Pesquisa em Ensino de Ciências no Brasil: Um Levantamento da Produção em Periódicos entre 1998 e 2008. Anais do VII Encontro Nacional de Pesquisa em Educação em Ciências, 12. http://posgrad. fae.ufmg.br/posgrad/viienpec/pdfs/518.pdf

Rocha, D., \& Deusdará, B. (2005). Análise de Conteúdo e Análise do Discurso: Aproximações e afastamentos na (re)construção de uma trajetória. Alea: Estudos Neolatinos, 7(2), 305-322. https://doi.org/10/bs2cvm

Sánchez, A. (1995). Cumbre: Corpus lingüístico del español contemporáneo: fundamentos, metodología y aplicaciones. Sociedad General Española de Librería.

Santos, A. R. dos, Sousa, R. S. de, \& Galiazzi, M. do C. (2018). A Análise Textual Discursiva na Pesquisa em Educação Química: A Categorização como Possibilidade de Ampliação de Horizontes. Iniciação \& Formação Docente, 4(2), 167-178. http://seer. uftm.edu.br/revistaeletronica/index.php/revistagedeles/article/view/2250

Santos, B. F., Vaz, Á. S., Leite, P. L., Barbosa, C. S., Araújo, L., Lyra, A. B., Santos, B., Moreira, C. B., Santana, M. L. A. D., \& Martins, R. B. (2017). O estudo dos métodos de análise em dissertações como aprendizagem e formação de pesquisadores para a pesquisa qualitativa: Relato de uma experiência. Revista Brasileira de Pós-Graduação, 14, 1-17. https://doi.org/10/ggkzb3

Sardinha, T. B. (2000). Lingüística de Corpus: Histórico e problemática. DELTA: Documentação de Estudos em Lingüística Teórica e Aplicada, 16(2), 323-367. https://doi. org/10/ct75cj

Sardinha, T. B. (2011). Metáforas e Linguística de Corpus: Metodologia de análise aplicada a um gênero de negócios. DELTA: Documentação de Estudos em Lingüística Teórica e Aplicada, 27(1), 01-20. https://doi.org/10/ggmk7x

Sinclair, S., \& Rockwell, G. (2016). Voyant Tools. Voyant Tools. https://voyant-tools.org/ 
Julio Murilo Trevas dos Santos

${ }^{\oplus}$ https://orcid.org/0000-0002-5691-9265

Universidade Estadual de Maringá Programa de Pós-Graduação em Educação para a Ciência e a Matemática Maringá, Paraná, Brasil

Universidade Federal da Fronteira Sul Campus Realeza Realeza, Paraná, Brasil jtrevas@uffs.edu.br

Neide Maria Michelan Kiouranis

${ }^{\oplus}$ https://orcid.org/0000-0002-1279-9994

Universidade Estadual de Maringá

Departamento de Química

Maringá, Paraná, Brasil nmmkiouranis@gmail.com

Submetido em 03 de março de 2020 Aceito em 17 de julho de 2020

Publicado em 19 de agosto de 2020 